\title{
OS ÍNDIOS, A CATEQUESE E A CIVILIZAÇÃO NO AMAZONAS (1845-1898): ENTRE O FRACASSO E A RESISTÊNCIA ${ }^{1}$
}

Bruno Miranda Braga ${ }^{2}$

\begin{abstract}
RESUMO
Neste trabalho, abordaremos alguns aspectos relevantes de como deu-se a política de Catequese e Civilização dos Índios no Amazonas. Ainda no período colonial, o Império do Brasil, tornou público o Decreto no 426 de 24 de julho de 1845, conhecido como Regulamento das missões, que ditava como devia dar-se o contato com os autóctones de então. Essa legislação perdurou durante a colônia, todo o Império. Com a instauração da República no Brasil, muitas coisas mudam e muitas permanecem, exemplo disso é que no estado do Amazonas surge de forma pioneira no alvorecer da República o Decreto $\mathrm{n}^{\circ} 248$ de 28 de maio de 1898, propondo inovações no serviço de catequese e civilização. Porém, o índio resiste, e isso se constitui num desafio atemporal para todos os políticos.
\end{abstract}

\section{PALAVRAS-CHAVES}

Índios, Catequese e Civilização, Amazonas, Província.

\section{INTRODUÇÃO: OS REPRESENTANTES DO PODER E OS ÍNDIOS: “CATIVAR PARA UTILIZAR”}

"A bistória dos indios é o opróbrio da nossa civilização. Apesar de tantas leis proclamando sua liberdade, e prescrevendo-a escravidão deles, esta subsiste quase de fato" Francisco José Furtado, presidente da Província do Amazonas, 1858 .

Pela Lei $n^{\circ}$ 582, de 05 de setembro de 1850, se instaura a Província no Amazonas, após uma longa fase colonial como pertencente ao estado do Grão Pará, os amazonenses conseguem emancipar-se de seu maior aliado e de seu maior inimigo também. A proposta de lei para a elevação do Amazonas a Província, ideia do deputado João Batista de Figueiredo Tenreiro Aranha sendo encaminhada para a aprovação do Imperador pelo ministro Jose da Costa de Carvalho, marquês de Monte Alegre. A capital da Província seria a Cidade de Nossa Senhora da Conceição da Barra do Rio Negro, essa nova unidade provincial teria direito a eleger um senador e um deputado à Assembleia Geral, e sua Assembleia legislativa seria composta por 20 membros.

O escolhido e nomeado pela Carta Imperial de 7 de junho de 1851 para ser o primeiro presidente foi João Batista de Figueiredo Tenreiro Aranha, um belenense, mas com raízes de uma família amazonense de Barcelos. Mas este somente assumiria formalmente seu posto em $1^{\circ}$ de janeiro de 1852 , dois anos após a instalação da Província.

Entre os assuntos elencados pelo Presidente da Província do Grão Pará, Dr. Fausto Augusto de Aguiar, na exposição de posse de Tenreiro Aranha, um merece especial atenção e foi uma "prioridade" na curta gestão do mesmo (de 01/01/1852 a 27/06/1852) foi a catequese e civilização dos índios arredios das Província. Augusto Aguiar, salienta que já existem 03 missões estabelecidas na região e, solicita que Tenreiro mostre especial atenção pois somente assim, a província ganharia muitas vantagens, à medida em que era "tão pobre de braços, como rica de recursos naturais,- com a civilização dessas hordas numerosas, que por seus extensos ermos vagueiam, arredadas da nossa sociedade, mas fáceis em geral pela docilidade de sua índole, de serem por elas conquistadas” (EXPOSIÇÃO, 1851, p. 07).

De fato Tenreiro Aranha manteve uma relação profícua com relação a catequese e civilização dos índios. Quando aqui chegou, logo destacou que o problema dos índios era falta de catequese e civilização. E que pouco se tinha feito pelos índios até então. O presidente aponta para o ano de 1845, e o Regulamento acerca das Missões de Catequese e Civilização dos Índios, que foi aprovado e publicado pelo Decreto Imperial n. ${ }^{\circ}$ 426, de 24 de julho de 1845. Segundo Patrícia Sampaio, essa legislação criou uma estrutura de aldeamentos indígenas, dispersando-os por todo o território do Império, sob a admi1 Versão alterada de Comunicação apresentada no XXVIII Simpósio Nacional de História ANPUH, realizado na cidade de Florianópolis em julho de 2015.

2 Professor, mestrando do Programa de Pós-Graduação em História da Universidade Federal do Amazonas. 
nistração de um Diretor Geral de Índios, que era nomeado por sua majestade o Imperador para atuar em cada província. Cada um desses aldeamentos, teria um Diretor de Aldeia, e um pequeno quadro de funcionários; e quanto a Igreja? Para os missionários competiria, "à tarefa relativa a catequese e à educação dos índios" (SAMPAIO, 2008). Porém nem tudo se cumprira como regia este regulamento. O próprio Tenreiro Aranha, nos diz que,

Se desde o ano de 1845, em que se expediu o Regulamento de 24 de Julho, se tivesse cuidado de o mandar pôr em execução nessa província, com os Missionários e os meios precisos, o primeiro Diretor Geral Nomeado por Sua Majestade O Imperador teria feito aparecer os melhoramentos, que iam fazendo aqui, apesar de contrariado e com tão poucos ou nem uns meios; [...]. Assim ficaram e achei os Diretores de Aldeias, quase todos com Títulos de Encarregados...” (RELATÓRIO, 1852).

Nisso vemos que a política imperial não estava alcançando seus objetivos no Amazonas, todos os presidentes da província vão apontar defeitos a críticas ferrenhas em suas falas, relatórios ao longo do oitocentos ao sistema de Catequese e Civilização. Mas em momento algum os mesmos apontam outra solução para o "problema dos índios".

Falta de missionários, violência por parte dos diretores, desídia desses diretores, brigas de diretores, diretores assumindo outros cargos públicos, são alguns dos problemas elencados pelos presidentes em virtude a catequese e civilização. Logo, na segunda metade do século XIX, as missões se constituíam não de uma simples ferramenta de propagação da fé cristã e combate a heresia, porém, de forma do governo, através da Igreja, impor aos índios seus mecanismos de civilização e transforma-los em mão-de-obra. Mas através de relatos do período, vemos que muitas vezes os índios abandonavam esses trabalhos sem se quer recorrerem a seus salários, o quê na visão ocidental era classificado como preguiça mas, podemos também encarar esses fatos de abandono como resistências e lutas as vezes silenciosas e estratégicas como teoriza Michel de Certeau, em A Invenção do Cotidiano (CERTEAU, 2012). A Igreja assim, operava como a intermediária (METCALF, 2009) os responsáveis agiam conforme a sua visão de mundo sendo que estes não eram os típicos missionários, desbravadores, que, lançavam-se nas regiões mais longínquas em nome da fé, mas antes eram funcionários da província e possuíam direitos e deveres.

Mesmo atribuindo salários aos sacerdotes para o exercício de Catequese, em 1855, o presidente da província, Conselheiro Herculano Ferreira Penna, informa que há apenas três Missionários atuando em toda a Província, Frei Gregório José Maria de Bene, Frei Pedro de Ceriana, Frei Joaquim do Espirito Santo Dias e Silva. O mesmo nos diz que já encaminhou uma solicitação ao Imperador e aguarda respostas (EXPOSIÇÃO, 1855).

Em 1858, o presidente provincial Francisco José Furtado faz um juízo de valor sobre o estado da catequese e civilização dos índios que se encontrava "em deplorável estado". Também mostra que os índios "sofrem toda a sorte de injustiças, violências e fraudes, não só de algumas autoridades subalternas, como dos seus próprios Diretores e particulares.” Nisso percebemos que os Diretores pouco estavam fazendo pelo serviço, e além do mais estavam colaborando para a escravização do indígena. Para o presidente, a metodologia mais eficiente para o avanço da catequese e civilização seria a presença de muitos e bons missionários, e estabelecer casas de educação, mas segundo o mesmo, é difícil encontrar pessoas para atuar na catequese, uma vez que poucas eram os que se dispunham a deixarem as suas cidades, essencialmente os que moravam em Manáos para se lançarem nos mais longínquos sertões do Amazonas de então. Para Francisco Furtado, "a história dos índios é o opróbrio da nossa civilização. Apesar de tantas leis proclamando sua liberdade, e prescrevendo-a escravidão deles, esta subsiste quase de fato". Ou seja, para o presidente, os índios lutam para defender-se. Os índios eram e continuam sendo havidos em conta de brutos e estranhos ao grêmio da humanidade. "Os índios foram sempre vítimas da avidez e 
maldade de seculares e eclesiásticos sem exceção da famosa ordem dos jesuítas.” Aqui o presidente aponta que todos estavam subordinando o indígena a seus interesses particulares. Para ele civilização podia ser considerado como

o livre desenvolvimento de todas as faculdades físicas e morais do homem sem outros limites, que os do direito e da justiça, que proclama a inviolabilidade da vida humana, pudesse aceitar como lei sua negação da sua personalidade, a destruição do homem em proveito de ignóbil cobiça (RELATÓRIO, 1858).

Nisto o presidente condena a escravidão do índio pois para ele os índios possuem aptidões e, "a Providência não condenaria uma raça inteira à destruição ou a escravidão em benefício de outra”. Em 1858, haviam apenas 02 missionários atuando no Amazonas, um em Tabatinga, outro em Uapés (RELATÓRIO, 1858). A falta de missionários persistiu no Amazonas em 1859. Segundo o presidente da província, os Diretores, estavam com inimizades para com os índios, e os classificavam como incapazes de realizar os trabalhos das obras públicas da Capital Manáos, fato que despertou a fúria de Francisco José Furtado, que afirmou que os diretores estavam conservando os índios "na ignorância para mantê-los sob sua exploração e espoliação.” Porém, o mesmo tendo recorrido ao Capitão José Casimiro Ferreira do Prado, em alguns dias "e sem violência alguma, foram apresentados ao presidente 40 índios". De acordo com o presidente, os índios não vinham "auxiliar" nas obras públicas, pois estavam sendo maltratados pelos diretores. Após a intervenção do Capitão Casemiro, vieram para as obras 155 índios, dos quais o presidente cedeu alguns à particulares a pedido destes sob a condição de proporcionarem aos índios $\mathrm{O}$ mesmo salário que receberiam nas obras públicas (RELATÓRIO, 1859).

Em 1860, o vice-presidente do Amazonas, Dr. Manoel Gomes Corrêa de Miranda, expõe de forma piegas a questão da falta de sacerdotes na região. Para este, as obras públicas que estão se fazendo na capital, tem contribuído muito para civilizar os índios. Os índios estavam vindo de diversas diretorias para serem empregados nas obras públicas de Manáos, e, o regime de trabalho era assim: os índios chegavam na capital, se apresentavam ao presidente de província, e estes permaneciam na cidade em seus ofícios por dois meses, sendo após esse período, substituídos, pagos e poderiam "retornar satisfeitos a seus lares" alguns dessistiam antes de concluir seus trabalhos, outro porém, se estendiam para além dos dois meses (EXPOSIÇÃO, 1860). Percebemos que os índios já não temiam tanto quanto antes, encarar o mundo dos "civilizados", o presidente informa que é crescente o número de índios que vem aos povoados oferecer seus serviços.

A situação da catequese e civilização dos índios na Província do Amazonas, não progredia de fato. Em 1862, algumas diretorias próximas a Manáos foram extintas sob o pedido do Diretor Geral, segundo Manoel Clementino Carneiro da Cunha, então presidente da província, estes índios já estavam nas condições de dispensar a tutela dos Diretores Parciais. Ou seja, alguns índios estavam cumprindo com os requisitos da civilização e já estavam prontos ao convívio social. Ou apenas o Diretor achou oportuno diminuir o número de tutelados que abrigava? O mesmo presidente reclama arduamente da má atuação dos Diretores, que mesmo recebendo demasiadas benesses, ainda "hostilizavam os índios e pouco fazem para se tornar pleno o contato" (RELATÓRIO, 1862).

Em 1872, o serviço parece ter uma evidente melhora. Em 1872, surge na Província do Amazonas a Lei no 239, de 25 de maio de 1872, que em seu discurso da autoridade ao Presidente da Província do Amazonas "a contratar até 15 sacerdotes de qualquer ordem religiosa, que se incubam da Catequese dos índios selvagens da Província” (COLLEÇÃO DAS LEIS DA PROVÍNCIA DO AMAZONAS, 1872, pp. 46-47). Esse contrato alude para outra questão bem interessante. Para uma compreensão profunda dos fatos humanos, ao longo de sua existência e de seu fazer histórico, o historiador britânico Peter Burke, nos propõem "ler os documentos nas entrelinhas" (BURKE, 2011, p. 26) problematizando 
tais fontes, fazendo perguntas seguindo a tradição historiográfica proposta pela Escola dos Annales, compreendendo os fatos inerentes à ação humana. Nesse sentido, é interessante perceber o contido nas entrelinhas dessa lei "da Catequese dos índios selvagens", ou seja, já existiam índios considerados civilizados, ou aptos para sociabilidade, e possivelmente convertidos à fé cristã.

O segundo artigo dessa lei, nos diz que,

Art. 2 - Os contratados terão seu centro nesta capital. Suas vantagens serão: passagens gratuitas por conta da Província desde o lugar do contrato, casa para moradia, subsidio proporcionado a suas necessidades, curativos em suas enfermidades e cem mil réis mensais de gratificação logo que partirem para as missões (COLLEÇÃO DAS LEIS DA PROVÍNCIA DO AMAZONAS, 1872, p. 46).

Portanto, havia um objeto comum: implantar a qualquer custo a civilização. Civilização era a palavra de ordem e alcançá-la significava não deixar vestígios da cultura indígena ligada ao atraso e ao hostil também. Monteiro (1994), analisando a colonização nos diz que os aldeamentos, objetivavam controlar os índios e adaptá-los a vida produtiva, mas isso ia pelos ares à medida que os índios resistiam bravamente e pouco abriam mão de sua cultura e de suas crenças.

Em 1883, para o Amazonas, seria o ano do basta! Ano que alguém de fato escancara o estado do serviço de catequese. José Lustosa da Cunha Paranaguá, presidente da província no período, afirma que os resultados da catequese e civilização dos índios são insignificantes na medida em que, "o antigo sistema de diretorias de índios é obsoleto, e sua legislação especial destinada a regularizar o trabalho é pouco satisfatória!”, afirma o presidente, e completa dizendo que o se conseguiu foram maus tratos e espoliações ao gentio. O presidente aponta que a educação dos índios deve ser antes de tudo uma “educação profissional, do que puramente mental e religiosa, como tem sucedido", para ele não bastava ensinar ao índio deveres religiosos e noções de leitura, "aliás imperfeitíssimas" (RELATÓRIO, 1883) é dever antes de tudo adestrar o índio para trabalhos mecânicos que revelam maior aptidão, nisso para o presidente o índio deveria ser preparado para trabalhar de forma funcional na província que tanto carecia.

A civilização dos índios era uma necessidade e todos os presidentes de Província dedicavam atenção, a ponto dessa necessidade torna-se uma meta de governo. Em 06 de Janeiro de 1898, assim discursava o então governador Fileto Pires Ferreira:

\section{Catechese e Civilisação dos Índios}

Não é razão que insisto na solução deste melindroso trabalho. Convenço-me cada vez mais que, a não ser muito excepcionalmente, as lutas entre os selvagens e os civilizados partem sempre de provocações d'este. Felizmente, graças às medidas tomadas, e a não ter-se fornecido mais forças que só serviam para massacre dos pobres aborígenes, temos atravessado um período de paz com eles (MENSAGEM, 1898, p. 4).

Vemos que o Presidente da Província Fileto Pires, tem consciência dos crimes cometidos pelos civilizados aos indígenas e os culpa por tais crimes, há uma romantização em seu discurso, no estilo Rousseauniano pois inspira (ROUSSEAU, 1989, p. 15), transmite alteridade e etnocentrismo ao propor a "figura do bom selvagem", onde o importante não é a sociedade, mas o viver humano. Isso é bem presente na história da Amazônia que "como a recriação do bom selvagem em ideias como a de povos da floresta e de ribeirinhos, demonstra um novo romantismo social” (PINTO, 2008, p. 15), ou seja, Dr. Fileto Pires, recria o bom selvagem visando estabelecer um novo discurso sobre o índio. Porém, não pensemos que a partir desta Mensagem acabaram a perseguição e desprezo aos índios, continuando a mensagem, o governador mostra seu real objetivo:

O índio é altivo, é não se submete ao aviltamento que fazem recair sobre sua raça, dali a luta, as mortes, o ódio encarniçado. O Governo pensa que aberto os rios habitados pelos aborígenes a uma navegação regular e constante, tratados estes por meio mais humanos e suasórios facilmente se fará 
a Catechese. O braço indígena pode muito ser aproveitado e convém não deixar permanecer o estado atual de cousas. Tenho em vista utilizar o serviço de missionários para chamarem os índios ao nosso meio (MENSAGEM, 1898, p. 41).

O governador deixa bem claro que a função do indígena é ser mão-de-obra, e o mesmo não se sente impedido de nenhuma forma para concretizar seu objetivo, e, utiliza-se dos serviços dos missionários para tornar realidade. Mas, isso era imperativo, uma vez que, "[...] todos - excluindo os índios, é claro-concordavam que a diminuição nua e crua proporcionaria a única maneira de garantir, de uma vez por todas o controle social e a exploração econômica dos indígenas" (MONTEIRO,1994, p. 41).

Se na colônia o índio era alvo do recrutamento para servir a Coroa, agora isso não era tão diferente. Com esta visão, evidenciamos que apesar e poderio do Estado e da Igreja enquanto instituições que visavam ditar um processo de civilizar, os índios lutavam para manter e preservar sua idiossincrasia, através de táticas (CERTEAU, 2012) que nos fazeres dos brancos eram exercidas, sem muitas vezes serem percebidas pelos que impunham o poder.

\section{NO ALVORECER DA REPÚBLICA SURGE O DECRETO Nº 248 NO ESTADO DO AMAZONAS}

"Nós indios, olhamos para esse mundo do homem branco e verificamos que essa civilização não deu certo." (Marcos Terena; do povo Terena)

A história política do Amazonas é bastante conturbada e complexa, cheia de tramas e episódios que fogem ao considerado normal no dia a dia. Fileto Pires, o então presidente da Província não terminou seu mandato, e, de 1898 a 1900, seu vice-governador José Cardoso Ramalho Júnior, assumiu a chefia. Esse, por meio de um decreto bem expressivo o Decreto $\mathrm{n}^{\circ} 248$, de 25 de Maio de 1898, estabelece e "Dá regulamento para o serviço de Catechese e Civilisação de Índios" (ESTADO DO AMAZONAS. DECRETO, 1898).

Trata-se de um documento oficial que dita como funcionaria o processo de civilização aos índios, por meio das missões. Como os encarregados deveria se portar nas mais diferentes situações, quais seus direitos, atribuições e obrigações, e os cargos administrativos que compõem tal serviço.

A palavra de ordem nesse documento é animar, animar os índios significava torná-los trabalhadores, seria despertar nos índios o interesse pela lavoura e pela agricultura para produzir gêneros para a Capital da Província -Manaus- e demais cidades, que estavam cada vez mais nos padrões de civilização e viraram palco de segregação social.

O Decreto em suas 23 páginas, verbaliza como se deveria atrair e condicionar o trato social do índio do Amazonas. Ao todo, é composto por 15 Artigos que predispõe como deverão atuar os empregados nessa tarefa. No Artigo $1^{\circ}$., é colocado que haverá uma Diretoria Geral sediada na capital, Manáos, e "tantas diretorias quanto forem necessárias", espalhadas no território do estado. No Artigo $2^{\circ}$, nos é apresentada a composição dos empregados no Serviço: para a diretoria Geral, sediada na capital, comporão 1 Diretor Geral e 1 Auxiliar. Para as Diretorias, fariam parte 1 diretor, 1 ajudante, e os intérpretes e ajudantes destes que se tornarem possível.

O Artigo $3^{\circ}$, dispõe sobre as atribuições do Diretor Geral. São 36 incisos, mostrando as diferentes tarefas do encarregado desta função. Competia a este examinar como estavam os burgos e as ocupações dos índios, sindicar os recursos da lavoura, propor separação ou reunião dos burgos, etc. em algumas atribuições, vemos uma transposição do Regimento de 1845. Segundo Sampaio 2008, sobre as funções do Diretor no Regimento de 1845:

Cabia ao Diretor geral a demarcação de terras do distrito da aldeia à presidência da província indicando outras modalidades passiveis de demarcação tal como já indicamos. Para tanto, era preciso determinar se o aldeamento possuía (ou não) patrimônio anterior, afinal, alguns deles eram coloniais 
(como é o caso do Maranhão e do Pará) e, portanto, deveriam possuir as léguas competentes asseguradas pela legislação. [...] o Diretor Geral ainda tinha outras obrigações com o Ministério: cabia-lhes informar as dificuldades na aplicação das novas determinações, apresentar à sua consideração os regulamentos ou instruções especiais para as aldeias em razão das especificidades locais e propor a tabela salarial de pedestres e oficiais das aldeias, incluídos os valores dos jornais dos índios que prestassem serviço nas aldeias ou fora delas (SAMPAIO, 2008, pp. 13-15).

Agora, o Diretor Geral, possuía atribuições de cunho político assim como em 1845, mas respondia perante o governador do Estado, proponde-lhe uma significativa melhora na produção agrícola, envolvida plenamente na questão do índio, pois esse despertar para a lavoura, faria dos índios responsáveis pela produção dos produtos para exportação e consumo no estado.

Se compararmos a função do Diretor Geral do Regimento de 1845, com o Decreto $n^{\circ}$ 248 de 1898, vemos atribuições idênticas em ambos, que podemos concluir foram reproduzidas de uma para outro. Por exemplo, o inciso $3^{\circ}$ do Regulamento de 1845, estabelece:

S. 3. ${ }^{\circ}$ Precaver que nas remoções não seja sejam violentados os Índios, que quiserem ficar nas mesmas terras, quando tenham bom comportamento, e apresentem um modo de vida industrial, principalmente para agricultura. Neste último caso, e enquanto bem se comportarem, lhe será mantido, e às suas viúvas, o usufruto do terreno, que estejam na posse de cultivar (SAMPAIO e ERTTHAL, 2006, pp. 298-309).

Já no inciso 5..$^{\circ}$ do Decreto ${ }^{\circ}$ 248, de 28 de maio de 1898, temos:

$\int 5^{\circ}$ Providenciar de modo que nas remoções não sejam os índios violentados, atendendo-se ao comportamento e laços vinculados ao terreno, principalmente a lavoura, mantendo-se em quanto se compuserem, o uso fruto do terreno para si e seus descendentes (ESTADO DO AMAZONAS, 1898, p. 5).

Isso acontece ainda com outros incisos ao longo do documento analisado, as questões ligadas a linguagem sofreram alterações porém, o objetivo é o mesmo mas antes de pensarmos na permanência escrita, temos de pensar na permanência de atos para o índio, e como este se mantivera como resistente ao processo lhe imposto. Esse diretor geral, era o responsável, podemos concluir de estabelecer os primeiros contatos com os índios, fazer propostas, enfim seduzir o indígena a fim de encaminhá-lo ao viver social. Não pensemos que isso era bom ou positivo ao índio, pois o objetivo proposto não era socializá-lo para desfrutar o gozo das elites ou da sociedade enriquecida, mas transformá-lo em mão de obra para sustentar essa elite com produções agrárias, por isso, a lavoura, agricultura assumiu papel salutar neste período. Pois é pelo meio rural que as cidades vão se desenvolver e se modernizar.

A proposta do governo era bem estratégica e clara como lemos no inciso 10. Dar aos índios roupas e outras quinquilharias, coisas sem valor para atrair sua curiosidade, fasciná-los, cegá-los, para obter suas "sympathias" a fim de trazê-lo para si, não para ter sua amizade, mas para fazê-lo aceitar algo que lhe seria imposto: \$14. Propor para os burgos importantes, não só quanto a sua população, mas também quanto ao seu desenvolvimento agrícola e industrial, a criação de escolas para ensino primário (ESTADO DO AMAZONAS, 1898, p. 6).

Aqui, as propostas são generalizadas e beneficiam a todos da comunidade. Onde lemos burgos, era a denominação dada agora aos lugares destinados à habitação indígena, seria algo inferior a cidade. No Regimento de 1845, lemos aldeias, aldeamentos, em 1898, eles são burgos. As escolas visavam formar nos índios uma mentalidade de trabalhadores torná-los aptos para o trabalho eram escolas de formação.

$\mathrm{O}$ artigo $4^{\circ}$, atribui as competências aos Diretores, os que atuariam in loco, nos burgos onde se encontravam os índios. Para esta função que, acreditamos ser a mais importante, o Decreto atribui 69 , incisos que prescrevem suas diversas atribuições, como,

$\$ 1^{\circ}$. Estabelecer comunicações diretas com os índios que se conservarem ainda, nas matas, errantes ou aldeados e fora da comunhão social, procurando animá-los a formar burgos agrícolas em lugares próximo de algum centro populoso e civilizado. 
$\$ 2^{\circ}$. Inquerir onde há índios em condições do $\$ antecedente, conhecer bem os seus costumes, estudar os seus dialetos e mandar o interprete só ou com este até os aldeamentos deles para se entender com eles mostrando-lhes as vantagens da vida social.

$\mathrm{O}$ artigo $5^{\circ}$. atribui as obrigações do ajudante, que exerceria as atribuições do Diretor em suas ausências, se responsabilizaria pelos pagamentos e auxiliaria o intérprete nos arrolamentos. No artigo $6^{\circ}$, dá-se as atribuições do intérprete, que substituiria o ajudante em suas ausências, que também era responsável pela circulação de livros nos burgos, informar como estava o desenvolvimento moral e material ou de decadência dos burgos, inspecionar o ensino das primeiras letras entre outras.

Por fim, o artigo $7^{\circ}$., apresenta a incumbência dos intérpretes, que substituiria o ajudante ou o diretor, assistiria nos pagamentos, acompanhar o intérprete nos descimentos, "ensinar a ler e escrever aos índios no burgo se não houver escolas". Os artigos restantes do decreto, expõe o que tange as nomeações, demissões e etc. (artigos, $8^{\circ}, 9^{\circ}, 10^{\circ}, 11^{\circ}, 12^{\circ}$, respectivamente), e os finais $\left(13^{\circ}, 14^{\circ}, 15^{\circ}\right.$ ), das disposições gerais. O mais interessante é que mesmo tratando da Catequese e civilização do índios, o Decreto 248, de 1898, em nenhum momento cita a questão da religião ou do doutrinamento cristão, nem mesmo missionários são elencados em seu quadro funcional, é claro que com a instalação da República no Brasil, uma das consequências foi a laicização do novo país, porém em se tratando de atividades de catequese e civilização, a resposta ainda era recorrer aos missionários, coisa que não acontece e nem aparece no documento analisado.

Segundos especialistas em História do Indigenismo no Brasil, o Regimento das Missões de Catequese e Civilização de Índios de 1848, foi o único instrumento legal da política indigenista de todo o século XIX, então como explicar a existência de uma legislação ou melhor de um Decreto que dá regulamento para o serviço de catequese e civilização de índios, está presente numa das unidades federativas do Brasil? Para essa questão apontamos duas possibilidades pois fazer história é estar aberto a um campo de possibilidades. Podemos acreditar que esse decreto foi uma forma de o governo do estado romper de vez com o regulamento de 1845, e tomar para si a responsabilidade para com os índios, tentando assim dar um basta no que estava acontecendo, é a primeira hipótese. Por outro lado, podemos aceitar que esse decreto foi uma antecipação do Amazonas em relação aos demais estados para a legislação de 1910, o Serviço de Proteção ao Índio -SIP, assim condicionando uma proposta à República nascente.

\section{CONSIDERAÇÕES FINAIS}

Em todo o contexto dos documentos e textos aqui apresentados, essencialmente o Decreto $\mathrm{n}^{\circ} 248$, de maio de 1898, salientamos que estes em seus conteúdos destacam o trabalho, fazem uma apologia a ele, pois se acreditava que não constituía um hábito dos indígenas trabalhar, menos ainda organizar uma classe trabalhadora. Todos os presidentes de províncias, acreditavam que com a catequese e civilização, os índios seriam uteis para a província, árduos trabalhadores, e estariam nos parâmetros de civilização de então.

Vemos com isso que a catequese e civilização dos índios tornou-se salutar entre as metas de governo, e um desafio de se cumprir. Alguns como vimos, propõem a extinção do arcaico sistema de Catequese e civilização, mas fato é que esse sistema perdurou durante toda a Colônia, todo o Império. Vale lembrar que pela localização geográfica do Amazonas, o número de sacerdotes era escasso e quem exercia estes cargos muitas vezes eram civis, designados pelo Secretário dos Negócios da Indústria. Nesses discursos sempre pretendiam transformar o índio da cidade, porém ele bravamente resistiu e lutou para conquistar seu espaço neste ambiente citadino, que se constituiu do local onde se dá significados através das relações, com o estado tornando-se cada vez mais alvo, era imperativo que se "escondesse" seu passado de tapera e se firmasse sua transformação em grande urbe. Percebe-se, que nas entrelinhas, 
o governo queria eliminar o índio, suas crenças, hábitos e costumes milenares. É importante perceber também a categoria de permanência histórica, a ponto de em pleno alvorecer do século XX, existirem legislações que ordenavam que o problema do índio, era problema de catequese, uma ideia ligada extremamente ao século XVIII e início do XIX, no período da Amazônia colonial portuguesa. Diferente do que aconteceu no império, que os missionários eram os únicos responsáveis pelo contato com os índios, no alvorecer da República no Amazonas, vemos pelo teor do decreto ${ }^{\circ} 245$, que civis foram incumbidos para tal, e se tornaram antes de tido, funcionários do estado.

\title{
THE INDIANS, A SUNDAY AND CIVILIZATION IN THE AMAZON 1845-1898: BETWEEN FAILURE AND STRENGTH!
}

\begin{abstract}
In this article we will discuss some important aspects of how gave up Catechesis policy and Civilization of the Indians in the Amazon. Even in the colonial period, the Empire of Brazil, published the Decree No. 426 of July 24, 1845, known as the Regulation of the missions, which would dictate how he should give up with the indigenous then. This legislation continued during the colony, the whole empire. With the establishment of the Republic in Brazil, many things change and many remain, example is that in the state of Amazonas comes a pioneer at the dawn of the Decree Republic No. 248 of May 28, 1898 , proposing innovations in the catechesis and civilization service. However, the Indian resists, and this is a timeless challenge to all politicians.
\end{abstract}

\section{KEYWORDS}

Indians, Evangelization and Civilization, Amazonas province.

\section{REFERÊNCIAS}

BURKE, P. (org.). A escrita da História: Novas Perspectivas. Trad. de Magda Lopes. São Paulo: Editora UNESP, 2011.

CERTEAU, M. A invenção do cotidiano: 1 Artes de Fazer. Trad. de Ephrain Ferreira Alves. Petrópolis, RJ: Vozes, 2012.

COLLEÇÃO DAS LEIS DA PROVÍNCIA DO AMAZONAS, t. XX, parte I: Lei n. 239, de 25 de maio de 1872. Manáos: Typographia do Amazonas, de Antônio Cunha Mendes, 1872.

ESTADO DO AMAZONAS. Decreto n. 248, de 28 de maio de 1898. Dá Regulamento para o Serviço de Catechese e Civilisação de Índios. Manáos: Imprensa Official, 1898.

EXPOSIÇÃO apresentada ao Exmo. Presidente da Província do Amazonas, João Batista de Figueiredo Tenreiro Aranha, por ocasião de seguir para a mesma Província, pelo Exmº. Presidente da do [sic] Grão Pará, Dr. Fausto Augusto de Aguiar, em 9 de Dezembro de 1851. Pará: Typ. de Santos \& Filhos, 1851.

EXPOSIÇÃO apresentada ao Exmo. Sr. Dr. Manoel Clementino Carneiro da Cunha, Presidente da Província do Amazonas pelo $1^{\circ}$ Vice Presidente da mesma Província o Exmo. Sr. Dr. Manoel Gomes Corrêa de Miranda por ocasião de passar-lhe a administração da mesma Província. Manáos, 24 de Novembro de 1860.

EXPOSIÇÃO feita pelo ao Exm ${ }^{\circ} 1^{\circ}$ Vice Presidente da Província do Amazonas, o Dr. Manoel Gomes Correa de Miranda pelo Presidente o Conselheiro Herculano Ferreira Penna, por ocasião de passar-lhe a administração da mesma Província. Em 11 de Maio de 1855. Cidade da Barra, Tupographia de Manoel da Silva Ramos, 1855.

MENSAGEM, do Exmo. Sr. Dr. Fileto Pires Ferreira, Governador do Estado. Lida perante o Congresso dos Representantes, por ocasião da abertura da primeira sessão extraordinária da terceira legislativa. Em 06 de Janeiro de 1898. Manáos Imprensa Oficial, 1898.

MENSAGEM, do Exmo. Sr. Dr. Fileto Pires Ferreira, Governador do Estado. Lida perante o Congresso dos Representantes, por ocasião da abertura da primeira sessão extraordinária da terceira legislativa. Em 06 de Janeiro de 1898. Manáos Imprensa Oficial, 1898.

METCALF, A. C. A Mulher como Intermediária. In: MORGA, Antônio Emílio e BARRETO, Cristiane Manique. (Orgs.) Gênero, Sociabilidade e Afetividade. Itajaí: Casa Aberta Editora, 2009.

MONTEIRO, J. M. Negros da Terra: Índios e Bandeirantes nas Origens de São Paulo: Companhia das Letras, 1994.

PINTO, R. F. Viagem das Ideias. Manaus: Valer, 2008.

RELATÓRIO apresentado à Assembleia Legislativa da Província do Amazonas pelo Exmo. Sr. Dr. Manoel Clementino Carneiro da Cunha, Presidente da mesma Província na Sessão Ordinária de 03 de Maio de 1862. 
RELATÓRIO apresentado à Assembleia Legislativa Provincial do Amazonas, na Abertura da Segunda Sessão da Decima Sexta Legislatura em 25 de Março de 1883, pelo Presidente José Lustosa da Cunha Paranaguá. Manáos. Impresso na Typographia do Amazonas de José Carneiro dos Santos, 1883.

RELATÓRIO que a Assembleia Legislativa Provincial do Amazonas apresentou na Abertura da Sessão Ordinária no dia 03 de Maio de 1859. Francisco José Furtado, Presidente da mesma Província. Manáos, Typographia de Francisco José da Silva Ramos, 1859.

RELATÓRIO que a Assembleia Legislativa Provincial dom Amazonas apresentou na abertura da Sessão Ordinária no dia 07 de Setembro de 1858 - Francisco José Furtado, Presidente da mesma Província. Manáos Typographia der Francisco José da Silva Ramos, 1858.

RELATÓRIO que, em seguida ao do Exmo. Snr. Presidente da Província do Pará, e em virtude da Circular de 11 de Março de 1848, fez sobre o estado da Província do Amazonas, depois da instalação dela, e de haver tomado posse seu $1^{\circ}$ Presidente o Exmo. Snr. Joao Batista de Figueiredo Tenreiro Aranha. Amazonas, Typ. de M. da S. Ramos, 1852.

ROUSSEAU, J. J. Discurso sobre a origem e os fundamentos das desigualdades entre os homens. In: ROUSSEAU, Jean-Jacques. Do Contrato Social e outros escritos. São Paulo: Cultrix, 1989.

SAMPAIO, P. M. e ERT'THAL, R. C. (Orgs.) Rastros da Memória: histórias e trajetórias das populações indígenas na Amazônia. Manaus: EDUA, 2006.

SAMPAIO, P. M. Politica Indigenista no Brasil Imperial. In: GRINBERG, K. e SALLES, R. (Orgs.) O Brasil Imperial (1808-1889). Rio de Janeiro: Editora Civilização Brasileira, 2008.

Data de recebimento: $23 / 01 / 2016$

Data de aceite: 08/03/2016 